\title{
Health Technology Assessment of smart canes for visually challenged in India
}

Authors: Fareen Choudhary ${ }^{1}$ and Kanchan Mukherjee ${ }^{2}$

1: MPH (Health Policy, Economics and Finance) student, Tata Institute of Social Sciences,

Mumbai

2: Professor, Centre for Health Policy, Planning and Management, School of Health System Studies, Tata Institute of Social Sciences, Mumbai, India

\section{Highlights}

1. First HTA on Assistive Technology in India

2. Mixed methods approach

3. Provides evidence for policy makers, provider organizations and smart cane manufacturers. 


\begin{abstract}
:
India has an estimated 4.6 million blind persons and over 35 million visually challenged. Safe, independent mobility when performing everyday tasks is one of the greatest challenges faced by the visually challenged. A smart cane is an assistive technology device which is helpful in obstacle detection and warning and also complements the functionality of the white cane. It helps to detect obstacles with the use of ultrasonic waves along with intuitive vibratory patterns. The federal/union government and various state governments in India are conducting camps to distribute smart canes to the visually challenged in India. Cost of a white cane is INR 150 (USD 2), while a smart cane costs INR 3000-3500 (USD 40-47) in the Indian market. With about 35 million blind or visually impaired in India, government policy initiatives at providing free smart canes is a huge expenditure. Hence, a Health Technology assessment (HTA) with a mixed methods approach using economic evaluation as well as in depth qualitative methods was conducted to provide evidence on value for this policy. A user perspective was used and the Psychosocial Impact of Assistive Devices Scale (PIADS) tool was used for generating utility score, and an in depth interview schedule was used for qualitative data.
\end{abstract}

The study results showed that the current smart canes are not cost-effective and have limitations in usability such as sensor not fully working in sunlight, inability to detect obstacles above four meters, limited use in rainy seasons, low battery, inability to guide directions in heavy traffic conditions, training requirement and higher cost. Findings from this study provide India-specific evidence on cost-effectiveness and usability of current smart canes. This evidence would be useful for policy makers, providers, and manufacturers of smart canes in India for changes in product design and inclusion of smart canes in priority assistive products list.

Keywords: Economic evaluation, Cost-utility analysis, PIADS, Assistive technology, mixed methods 


\section{Introduction}

The recently released world report on vision (WHO, 2019) reports that globally, at least 2.2 billion people have a vision impairment, of which at least 1 billion have a vision impairment that could have been prevented or has yet to be addressed. This is estimated to cost the global economy over USD 3 trillion every year in lost productivity and health and social care (Gordois, 2012). The report identifies that the burden of vision impairment is greater in lowand middle-income countries and underserved populations, such as women, migrants, indigenous peoples, persons with disabilities and rural communities. Most people who are blind or had moderate and severe vision impairment are living in South Asia, East Asia, and Southeast Asia (Bourne, 2017).

\section{Current Indian Scenario}

The Indian national blindness \& visual impairment survey report (2019), estimates the prevalence of blindness as $1.99 \%$ in population aged over 50 years and $0.36 \%$ in all age groups. The national programme for control of blindness (NPCB) was launched in 1976 in India as a federal government sponsored programme with the goal of reducing the prevalence of blindness to $0.3 \%$ by 2020 .

\section{Assistive Devices}

Assistive devices are external devices that are designed, made, or adapted to assist a person to perform a particular task. Many people with disabilities depend on assistive devices to enable them to carry out daily activities and participate actively and productively in daily life. The convention on the rights of persons with disabilities, articles 4, 20 and 26, asks nations to promote the availability of appropriate devices and mobility aids, and provide accessible information about them (UN, 2007). But in many low-income and middle-income countries, only $5-15 \%$ of population can access essential assistive devices and related technologies (WHO). Also, in most of these countries, production is very low and often of poor quality, with very few trained personnel and prohibitive costs.

Access to assistive devices is essential for many people with disabilities and plays an important role in their daily activities. Without assistive devices, people with disabilities may find it difficult to be independent in terms of getting education or ability to work. With the growing number of people with disabilities worldwide, many researchers are establishing various technologies to assist the disabled people in performing their daily tasks. 
Technologies used to assist with performing daily tasks are called Assistive Technology (AT). However, developing an AT is expensive, which increases its market cost (Herman, 1999).

After white cane (folding cane) was developed in the mid-1940s, it has been found to be the most frequently utilized portability help (Roentgen, 2008) by the visually disabled individuals, due to its cheap cost and lightweight convenient body (Shoval, 2000). Nonetheless, white canes can detect potential danger or obstacles/barriers only within $\leq 1$ meter and at knee level. The primary challenge with the utilization of the white cane is its failure to detect obstacles past the cane's height (1.25-2 meters) (Nichols, 1995), which restricts the cane user's mobility to a limited short range. A review (Manduchi, 2011) conducted on 300 visually challenged individuals found that half of the respondents experienced falling injuries once a year with a white cane. To address these issues, numerous electronic mobility assistive devices (EMAs) have been created as alternatives to the white cane since World War II (Strelow, 1982). Roentgen et al. suggested that electronic portability is required to improve the essential elements of mobility devices for the visually challenged.

An essential element of a visually challenged aid device is head-stature barriers recognition, as head wounds are a notable and repetitive issue for the visually impaired. A study conducted by the University of Mumbai on 300 visually impaired and totally blind individuals reported that $98 \%$ of the participants using white canes claimed at least one encounter of head-related injuries. Moreover, $23 \%$ of those encountered injuries required immediate medical attention, of which some also required dental treatment (Manduchi, 2011). The study recommended that the majority of these wounds or injuries could have been avoided by utilizing a supplementary device to identify obstacles for head-level. The same study indicated that $26 \%$ of the head-related injuries were the main cause for loss of confidence as independent explorers and loss of independence in the long run among visually impaired (Manduchi, 2011). In this context, smart cane was developed to facilitate the mobility of the visually impaired for independent exploration and navigation. Ultrasonic sensors detect and alert the user to stay away from obstacles or items in front of the smart cane and cautions visually challenged individuals about obstacles, pit and water ahead, which could reduce the risk of physical injuries. Smart cane use improved obstacle awareness by $57 \%$, diminished barriers impact rate by $91 \%$, expanded the mean distance location by 2.6 and thus improved safety for the visually challenged individuals (Singh, 2015). In spite of these advantages, smart cane has some limitations. Previous studies and our pilot study indicated issues such as less battery backup and continuous vibration in crowded places, 
which created confusion. High cost was also found to be an issue. Absence of explicit training for smart cane use, and availability and accessibility in rural area also affect the use of smart canes. However, smart cane distributions have been organized by the federal/union and state governments of India. In this context, this study attempted to provide evidence to policy makers, manufacturers and voluntary organizations working with the blind on the costeffectiveness of smart canes, and also provide recommendations.

\section{Methodology}

This was a mixed method exploratory study. A cost-utility approach using validated Psychosocial Impact of Assistive Devices Scale (PIADS) tool was used. Also, interviews were conducted with smart cane and white cane users to understand their experiences and issues associated with use of these canes. Incremental cost-effectiveness ratio (ICER) was calculated, and facilitators and barriers to use of smart canes were identified.

Primary data was collected by in-depth interviews, including questions related to cost, willingness to pay and PIADS utility score to analyze the effectiveness. Peer-reviewed articles from international and national journals were used for secondary data review. As this research focused on accessibility, affordability and availability of smart cane for the blind, user's perspective was used. Snowball and purposive sampling were conducted for the interviews. Visually impaired resource centers and educational institutes in Mumbai was the starting point for snowball sampling.

Sample size was calculated according to prevalence rate of blindness in India (as per last NPCB data). In order to calculate the sample size, the prevalence-based formula was used: $(1.96)^{2} *$ prevalence $(p)^{*}(1-p) /$ expected level of error $(L)^{2}$. Assuming $50 \%$ non-responders, and $5 \%$ error a target sample of 50 was calculated. After obtaining written informed consent, 24 smart cane users and 26 white cane users were interviewed. Sample matching was performed in order to have equal proportion of gender, age distribution, duration of cane use, category of blindness across both groups. Age group of participants ranged between 18-45 years, and $\geq 80 \%$ visually challenged diagnosed as per NPCB guidelines were included in the study. Cane users having less than one year experiences (new cane users) were excluded.

The PIADS tool was pilot tested and modified to reflect the local context. In the modified PIADS utility scale, three subscales that measure the impact in the domains of competence, adaptability, and self-esteem were considered. It is a rating scale where responses are 
evaluated from -3 to +3 ; with -3 signifying "most extreme negative effect" and +3 indicating "greatest positive effect". Zero means no apparent effect.

Standard decision rules using the cost effectiveness plane were considered to assess the costeffectiveness of the smart cane. Difference in utility score (effect) of smart cane (Es) with white cane $(\mathrm{Ew})\left[\left(\Delta E=E_{s}-E_{w}\right)\right.$; incremental effect] was compared with the difference in cost of smart canes $(\mathrm{Cs})$ and white canes $(\mathrm{Cw})\left[\Delta C=C_{s}-C_{w}\right)$; incremental cost]. Data analysis was performed using SPSS software and Microsoft Excel Version 2017. ANOVA and t-test were used to identify any significant difference between the mean scores of smart cane and white cane users.

Ethical considerations: The university (TISS) IRB guidelines were followed at all stages of the research. The scientific and ethical aspects of the proposal was approved by the school before data collection was started. Written informed consent was obtained from all participants after providing information about the study and its purpose in local language. Confidentiality was maintained and no names were recorded. Respondents had the option to withdraw at any point during the study.

\section{Results}

Of the 26 white cane users, 21 were male and five were female. Among the 24 smart cane users, 19 were male and five were female. Education level was found to be higher among daily smart cane users, with $45 \%$ being post-graduates and $20.8 \%$ being MPhil-PhD students. First source of information regarding white cane was obtained through friends and family in $40 \%$ of cases, whereas $44 \%$ of smart cane users obtained information from college or through media (social media, newspaper) or friends.

Majority of white cane users bought their canes from the National Association of Blind (NAB). In the case of smart cane, $75 \%$ of users bought the cane from a trust run though a college in Mumbai. The participants reported very few web-based options for buying either of these canes.

Most of the smart cane users were employed or pursuing higher education through scholarship, and were relatively financially better off than the white cane users. Employment status was directly associated with affordability and accessibility of smart cane, as cost of the smart cane was nearly 10 times more than the white cane. 
Reliability and correlation analysis of the PIADS tools and items was done and internal consistency was assessed using Cronbach's alpha. Values for the PIADS score were 0.878 for white cane and 0.725 for smart cane with a high reliability coefficient (Cronbach's alpha $=$ 0.907). In case of white cane inter-item correlational analysis yielded a mean (with respect to competence mean score) of 0.814 for adaptability and 0.718 for self-esteem. In case of smart cane inter-item correlational analysis yielded a mean (with respect to competence mean score) of 0.632 for adaptability and 0.753 for self-esteem. The analysis suggests that the PIADS is a reliable, valid, and responsive measure, with good clinical utility and is a sensitive measure of the effect of assistive technology, in visually challenged adult populations.

Economic Evaluation findings:

Tables 1 and 2 list the cost/utility score for white cane and smart cane users and Table 3 gives the Incremental Cost Effectiveness Ratios (ICER). The total cost incurred by each individual white cane and smart cane user included the cost of the cane, maintenance cost incurred in one year, along with any repair or associated costs.

Table 1. Cost/Utility score table for white cane use

\begin{tabular}{|c|c|c|c|}
\hline \multirow{2}{*}{ White cane } & Total Mean Cost & Mean Utility Score & $\begin{array}{c}\text { Cost/Utility } \\
\text { score }\end{array}$ \\
\cline { 2 - 4 } Utility score & 458.65 & 34.38 & 13.34 \\
\hline Competence utility \\
score
\end{tabular}


Table 2. Cost/Utility score table for smart cane use

\begin{tabular}{|c|c|c|c|}
\hline Smart cane & Total Mean Cost & Mean Utility Score & Cost/Utility score \\
\hline Utility score & 3154.16 & 17.29 & 182.42 \\
\hline $\begin{array}{c}\text { Competence utility } \\
\text { score }\end{array}$ & 3154.16 & 7.7 & 409.63 \\
\hline $\begin{array}{c}\text { Adaptability utility } \\
\text { score }\end{array}$ & 3154.16 & 4.95 & 637.20 \\
\hline $\begin{array}{c}\text { Self-esteem utility } \\
\text { score }\end{array}$ & 3154.16 & 6.16 & 512.03 \\
\hline
\end{tabular}

Table 3. Incremental Cost-Effectiveness Ratio - ICER

\begin{tabular}{|c|c|c|c|}
\hline Cane User - ICER & Cs-Cw & Es-Ew & ICER \\
\hline ICER (overall) & 2695.51 & -17.09 & -157.72 \\
\hline $\begin{array}{c}\text { Competence } \\
\text { subscale }\end{array}$ & 2695.51 & -10.59 & -254.53 \\
\hline $\begin{array}{c}\text { Adaptability } \\
\text { subscale }\end{array}$ & 2695.51 & & -1166.88 \\
\hline Self-esteem subscale & 2695.51 & -2.31 & \\
\hline
\end{tabular}

Since, incremental cost is positive and the incremental effect is negative, smart cane is unequivocally not cost-effective from the beneficiary perspective (poorer outcomes at higher cost). On the basis of t-test, competence subscale mean scores were found to be significantly different. An independent t-test indicated that those who used their canes for longer period of time along with proper well organized and structured training scored higher on the PIADS, 
expressed lesser degree of frustration and embarrassment, a higher level of Quality Of Life (QOL) and a greater ability to participate than those who were less exposed to trainings. White cane use showed higher positive impact on competence, adaptability and self-esteem than smart cane users.

Qualitative findings:

Only $50 \%$ of smart cane users where able to understand vibration patterns and hear audio beeps to know obstacle distances. Smart cane is powered by rechargeable battery, which $70 \%$ users found difficulty in recharging whenever required as it discharged rapidly. With special beep pattern, this feature was liked by many users. Many users confirmed the use and benefit of this feature during their regular mobility in natural environments.

More than $80 \%$ of the smart cane users had difficulty in making appropriate sensor adjustments, due lack of proper training. Nearly $77 \%$ of the users found the device effective in detecting above knee obstacles, but there was difficulty in detecting overhead hanging wires or poles or hanging branches. The most important functionality of smart cane from the usage point of view was effective path finding and collision avoidance in real environments. The handle grip design of the smart cane was found to be accommodative. Users who underwent mobility training were observed appreciating the handle grip. Central portion of device grip has a rough texture on both sides. Its purpose is to prevent accidental slip during usage due to various factors such as sweat, water, etc. Nearly $80 \%$ of the users were comfortable with the weight of the device while $20 \%$ users favored further reduction in weight of the device, especially for women users. Numerous smart cane users found that they may not identify the nature of obstacles, but sensed the presence of an object in the surrounding within the range.

Most of the users reported that either white cane or smart cane is essential everywhere and they prefer using it for the essential daily needs associated with mobility. Almost everyone preferred smart cane usage for travelling on roads and footpaths for independent journey to and from their residence to their school/college or office. This helped to encourage independent mobility, which in turn boosted the self-confidence. Canes were widely used to get to modes of transport like bus stops, railway stations, metro station and airports. However, smart cane users found it difficult to use smart canes in local trains due to overcrowding. Many reported that they often use the cane in parks and around residential areas for morning and evening walks. 
Cane was also used to avoid socially awkward situations like unwanted physical contact. Sense of control over mobility was higher among white cane users (48\%) as compared to smart cane users (35\%). Study participants perceived the white cane to be more durable with lower maintenance cost, and $75 \%$ of participants found white cane to be convenient as they were more accustomed to it. Productivity was found to be improved in $35 \%$ of smart cane users. As smart cane is a supplement to white cane but not a replacement, most smart cane users did not consider it worthwhile spending the extra amount for adding sensors to the cane.

Mobility training emerged as an important factor for usage of both canes. $84 \%$ of white cane users had undergone formal training. Of these, $44 \%$ took three and half months of formal training, while $28 \%$ underwent one and half months' mobility training. In case of the smart cane, $70 \%$ had undergone some training, of which $40 \%$ only received orientation or few hours training for one day during distribution of the smart cane. Recently many distribution camps for assistive devices have been organized by the federal and state governments, but these camps do not provide any training or education on maintenance. Smart cane use is easier for those who learn mobility through mobility training (especially pencil holding style is important). For smart cane, one needs to understand the different angles (to adjust the sensor in order identify the obstacle) and vibration pattern change, as one approaches the obstacle. To monitor the training, specific well trained professionals from government agencies or Non-Government Organizations (NGOs) should be present at the time of smart cane distribution especially in colleges, schools or during mass distribution. Most of the participants were willing to pay more for any upgraded technology, which further facilitates their mobility and improve their quality of the life.

\section{Discussion}

This study found that the use of mobility devices had a positive impact on psychosocial factors, particularly self-esteem and adaptability. As the calculated incremental cost was positive and the incremental effect was negative, smart cane was unequivocally not costeffective from the beneficiary perspective. Poorer outcomes at higher cost was found. Along with high cost and poor utility, respondents also highlighted issues such as limited use in crowded places wherein it was very difficult to detect or identify obstacles or even understand the path. The sensor detected multiple objects around it in crowded places, such as railway stations, parking spaces, markets and shopping malls, which resulted in continuous 
vibration thereby causing confusion. Hence, users had to switch off the vibration sensors and use it as white cane and tap the floor to understand the path in such crowded places.

Introduction of new technology is meant to improve utility in general and facilitate the mobility in day to day activities. However, smart cane users found it to be more complex in nature requiring excessive attention or it might mislead them. Importantly, visually challenged individuals who are using and exposed to white cane since few decades have to address issues related to adaption of new technology in their daily routine. With new modules of mobility training for smart cane and with more exposure to mobility technology, it might be possible change their opinions. According to the beneficiaries, the smart canes have some technological glitches, which require immediate attention. However, due to limited service centers and high cost for repair, users switched to white cane.

There is no proper Information, Education, Communication (IEC) developed or marketing strategy used or developed for this product. No information regarding its maintenance or servicing was given. Smart cane durability is low, since sensors can break easily during collision. Provider responses suggested that vibrator and sensor can only be fitted on a thin cane or else the smart cane will become bulky to carry. However, this increases the fragility of the smart cane. Thus, new technology intervention should be tested in both clinical and natural settings. The results of this study indicate that the professional services provided for smart cane selection and training were ineffective. Service providers and policy makers should be more cognizant of the potential effects of cost on assistive device outcomes. Those who use a white cane seem to experience fewer restrictions and limitations. Hence, white cane is associated with better mobility and is more cost-effective in the current scenario. The study findings suggested a scope for manufacturers to redesign the smart cane to make it more acceptable and cost-effective.

\section{References}

1. Brabyn, J. A. (1982). Locomotion of the blind controlled by natural sound cues. Perception, 11(6), 635-640. https://doi.org/10.1068/p110635

2. Bourne, R.R.A., et al. (2017). Magnitude, temporal trends and projections of the global prevalence of blindness and distance and near vision impairment: a systematic review and meta-analysis. Lancet Global Health,5(9), E888-897.

https://doi.org/10.1016/S2214-109X(17)30293-0 
3. DGHS (MOHFW) and AIIMS (2019). National Blindness \& visual impairment survey India 2015-19. Summary report. https://npcbvi.gov.in/writeReadData/mainlinkFile/File341.pdf

4. Gordois, A., et al. (2012). An estimation of the worldwide economic and health burden of visual impairment, Global Public Health 7: 5,465-481.

5. Herman, N.J. (1999). Deviance: The Symbolic Interactionist Approach- The Making of Blind Men. 24: 236-241. Dix Hills N.Y.

6. Manduchi, R., Kurniawan, S. (2011). Mobility-related accidents experienced by people with visual impairment. Research and Practice in Visual Impairment and Blindness,4(2),44-54.

https://pdfs.semanticscholar.org/609b/3d62282eaa5c2e4a89c803c0b401a789e27d.pdf

7. National programme for control of blindness \& visual impairment ( NPCB \& VI 2019)

https://dghs.gov.in/content/1354_3_NationalProgrammeforControlofBlindnessVisual. $\underline{\operatorname{aspx}}$

8. Nichols, A. (1995). Why Use the long White Cane? National Federation of the blind. http://www.blind.net/alternative-techniques/mobility/why-use-the-long-whitecane.html

9. Roentgen, U. R., Gelderblom, G. J., Soede, M., \& de Witte, L. P. (2008). Inventory of Electronic Mobility Aids for Persons with Visual Impairments: A Literature Review. Journal of Visual Impairment \& Blindness, 102(11), 702-724. https://doi.org/10.1177/0145482X0810201105

10. Shoval, S., Ulrich, I, Borenstein, J. (2000). Robotics-Based Obstacle-Avoidance Systems for the Blind and Visually Impaired. IEEE Transaction on Robotics and Automation, 10(1),19-20.

http://citeseerx.ist.psu.edu/viewdoc/download?doi=10.1.1.7.9335\&rep=rep1\&type $=p$ $\underline{\text { df }}$

11. Singh, V., et al. (2015). Smart cane for the visually Impaired: Design and controlled field testing of an affordable obstacle detection system. http://assistech.iitd.ernet.in/doc/Transed2010_Smart_Cane.pdf

12. Strelow, E. R., \& Brabyn, J. A. (1982). Locomotion of the Blind Controlled by Natural Sound Cues. Perception, 11(6), 635-640. https://doi.org/10.1068/p110635 
13.United Nations. Convention on the Rights of Persons with Disabilities: resolution / adopted by the General Assembly, 24 January 2007, A/RES/61/106, available at: https://www.refworld.org/docid/45f973632.html

14.World Health Organization. (2019) . World report on vision. World Health Organization. https://apps.who.int/iris/handle/10665/328717

15.WHO. Disability. Assistive devices and technology https://www.who.int/disabilities/technology/en/. 